\title{
Tumor Necrosis Factor Alpha Promoter Polymorphism and Severity of Acute Kidney Injury
}

\author{
Paweena Susantitaphong ${ }^{a, d}$ Mary C. Perianayagam ${ }^{a}$ Hocine Tighiouart $^{b}$ \\ Orfeas Liangos $^{c}$ Joseph V. Bonventre ${ }^{e}$ Bertrand L. Jaber ${ }^{a}$ \\ aDepartment of Medicine, Division of Nephrology, Kidney and Dialysis Research Laboratory, St. Elizabeth's Medical \\ Center, Tufts University School of Medicine, b Biostatistics Research Center, Tufts Medical Center, and ' Renal Division, \\ Brigham and Women's Hospital, Boston, Mass., USA; ${ }^{d}$ Extracorporeal Multiorgan Support Dialysis Center, Division of \\ Nephrology, Department of Medicine, King Chulalongkorn Memorial Hospital, Faculty of Medicine, Chulalongkorn \\ University, and Inter-Department Program of BioMedical Sciences, Faculty of Graduate School, Chulalongkorn \\ University, Bangkok, Thailand; and eIII Med. Klinik, Klinikum Coburg, Coburg, Germany
}

\section{Key Words}

TNFA gene · Polymorphism - Acute kidney injury · KIM-1 . NAG $\cdot a-G S T$

\section{Abstract \\ Background: Tumor necrosis factor-alpha is a proinflam- matory cytokine that has been implicated in the pathobiol- ogy of acute kidney injury (AKI). Methods: We explored the association of a functional polymorphism in the promoter region (rs1800629) of the TNFA gene with severity of AKI, as defined by level of glomerular filtration (serum cystatin $C$ and creatinine) and tubular injury (urinary NAG, KIM-1, $\mathrm{a}-\mathrm{GST}$, and $\pi-\mathrm{GST}$ ) markers, in 262 hospitalized adults. $\boldsymbol{R e}$ - sults: In unadjusted analyses, compared with the GG geno- type, the TNFA GA and AA genotype groups tended to have higher enrollment $(p=0.08)$, peak $(p=0.004)$, and discharge $(p=0.004)$ serum creatinine levels, and the AA genotype tended to have a higher enrollment serum cystatin $C$ level $(p=0.04)$. Compared with the GG genotype, the TNFA GA and $A A$ genotype groups tended to have a higher urinary KIM-1 level $(p=0.03)$, and the AA genotype group tended to have a higher urinary $\pi$-GST level $(p=0.03)$. After adjust-}

ment for sex, race, age, baseline estimated glomerular filtration rate, sepsis, and dialysis requirement, compared with the GG genotype, the TNFA minor A-allele group had a higher peak serum creatinine of $1.03 \mathrm{mg} / \mathrm{dl}(0.43,1.63 ; \mathrm{p}=$ 0.001 ) and a higher urinary KIM-1 (relative ratio: 1.73; $95 \%$ Cl: $1.16,2.59 ; p=0.008$ ). The TNFA minor A-allele group also had a higher Multiple Organ Failure score of $0.26(95 \% \mathrm{Cl}$ : $0.03,0.49 ; p=0.024$ ) after adjustment for sex, race, age, and sepsis. Conclusions: The TNFA rs1800629 gene polymorphism is associated with markers of kidney disease severity and distant organ dysfunction among patients with AKI. Larger studies are needed to confirm these relationships.

Copyright ๑ 2013 S. Karger AG, Basel

\section{Introduction}

Acute kidney injury (AKI) is a powerful predictor of in-hospital death and is associated with resource utilization, including prolonged hospital length of stay and increased healthcare expenditures [1-3]. AKI has also been variably linked to long-term risk of chronic kidney disease, kidney failure, and death $[4,5]$. In recent years,

\section{KARGER}

E-Mail karger@karger.com

www.karger.com/nec
(C) 2013 S. Karger AG, Basel

$1660-2110 / 13 / 1232-0067 \$ 38.00 / 0$
Bertrand L Jaber, MD, MS

St. Elizabeth's Medical Center

736 Cambridge Street

Boston, MA 02135 (USA)

E-Mail bertrand.jaber@ steward.org 
there has been interest in deciphering the role of genetic polymorphisms as potential determinants of adverse outcomes in patients with AKI [6-13].

In experimental settings, ischemia-reperfusion and nephrotoxic injury induce the generation of proinflammatory cytokines, which result in morphological and functional changes in glomerular endothelial and tubular epithelial cells [14-16]. Moreover, cytokines can also mediate distant organ injury $[17,18]$. High circulating levels of tumor necrosis factor-alpha (TNF- $\alpha$ ) have been associated with adverse clinical outcomes in patients with AKI [19]. Functionally relevant polymorphisms within the promoter region of the TNF- $\alpha$ (TNFA) gene, which affect transcriptional activity [20], have previously been linked to adverse clinical outcomes in critically ill patients [2123], including those with AKI requiring dialysis [6]. In the present study, in a cohort of hospitalized adults with AKI, we explore the association of a functional polymorphism in the promoter region (position-308) of the TNFA gene (rs1800629) with kidney disease severity, including glomerular filtration markers and urinary tubular injury markers.

\section{Methods}

\section{Study Population}

Hospitalized patients with AKI were recruited from two acute care hospitals (Boston, Mass., USA) between November 2003 and January 2007. All eligible patients were 18 years or older and received in-hospital nephrology consultation for AKI. AKI was defined as a rise in serum creatinine by $0.5,1.0$, or $1.5 \mathrm{mg} / \mathrm{dl}$ from a baseline level of $\leq 1.9,2.0-4.9$, or $\geq 5.0 \mathrm{mg} / \mathrm{dl}$, respectively [24]. This definition was adopted prior to the development of the AKI network consensus definition [3]. Exclusion criteria were age $<18$ years, pregnancy, chronic dialysis, organ transplantation within the prior year, and urinary obstruction. Institutional review board approval was granted and informed consent was obtained for each subject.

\section{Data Collection}

Medical records were reviewed prospectively to retrieve data on each subject, including demographic characteristics, coexisting conditions, hospitalization course, and outcomes. Sepsis was ascertained using the systemic inflammatory response syndrome criteria [25]. Two severity-of-illness scores were calculated, the Acute Physiology and Chronic Health Evaluation (APACHE) II score [26] and the Multiple Organ Failure (MOF) score [27]. Preexisting chronic kidney disease was defined on the basis of a baseline estimated glomerular filtration rate (eGFR) $<60 \mathrm{ml} / \mathrm{min} / 1.73 \mathrm{~m}^{2}$, which was calculated using the Modification of Diet in Renal Disease study equation [28]. At enrollment, AKI was reclassified according to the AKI network staging system, using serum creatinine-based criteria [3]. For biogeographic ancestry, self-identified ethnicity was used.

\section{DNA Extraction and Genotyping Analyses}

At enrollment, EDTA-anticoagulated whole blood was collected, aliquoted into cryotubes and stored at $-80^{\circ} \mathrm{C}$. Genomic DNA was extracted from leukocytes using a spin column method (Qiagen Inc., Valencia, Calif., USA). A commercially available polymerase chain reaction (PCR) technique (One Lambda Inc., Canoga Park, Calif., USA) was used to analyze single nucleotide allelic variations in the promoter region of the TNFA gene at position -308, using sequence-specific oligonucleotide primers [29]. In brief, a PerkinElmer 9600 thermocycler (Perkin-Elmer-Cetus, Norwalk, Conn., USA) was used to amplify the promoter regions by PCR. An internal control primer pair was included in every PCR reaction to exclude nonspecific DNA amplification. Amplified DNA fragments were separated by agarose gel electrophoresis and stained with ethidium bromide, and the bands were visualized under ultraviolet light.

Two blinded investigators classified the TNFA genotypes as low (GG), intermediate (GA), and high (AA) producer genotypes, based on in vitro transfection studies using constructs of the minor allele and human studies [30].

\section{Serum Measurement of Glomerular Filtration Markers}

Creatinine was measured by a modified Jaffé method, using a Beckman DxC 800 analyzer (Beckman Coulter, Brea, Calif., USA). Plasma cystatin $\mathrm{C}$ was measured by immunonephelometry using the BN II System (Siemens Healthcare Diagnostics, Deerfield, Ill., USA).

\section{Urinary Measurement of Tubular Injury Markers}

Urinary NAG (N-acetyl- $\beta$-D-glucosaminidase) activity was measured by a colorimetric assay (Boehringer Mannheim, Mannheim, Germany). The inter- and intra-assay coefficient of variation was 4.3 and $6.0 \%$, respectively. As part of a previously reported study, urinary KIM-1 was measured in a subset of patients $(n=204)$ by a microsphere-based Luminex assay [31]. The inter- and intraassay coefficient of variation was $<10.0 \%$. $\alpha$-GST and $\pi$-GST were measured by sandwich ELISA (Argutus Medical Ltd., Dublin, Ireland). The inter- and intra-assay coefficient of variation was 9.1 and $8.0 \%$ for $\alpha$-GST and 7.5 and $2.0 \%$ for $\pi$-GST, respectively. All measurements were performed in duplicate. All urinary biomarker levels were normalized to urinary creatinine and expressed as $\mathrm{mU} / \mathrm{mg}$ (for NAG) or ng/mg (for KIM-1, $\alpha$-GST, and $\pi$-GST).

\section{Statistical Analysis}

The genotype frequencies were tested for Hardy-Weinberg equilibrium using a standard $\chi^{2}$ test for any deviation of the observed frequencies. Comparisons between genotype groups were made by ANOVA and the Kruskal-Wallis test for continuous variables, and by $\chi^{2}$ or Fisher's exact test for categorical variables. Continuous variables are reported as means (SD) or medians (with 25 th and 75 th percentile) according to their distribution. Categorical variables are reported as counts (\%).

Multiple linear regression analyses were used to evaluate the association of the TNFA gene polymorphism with filtration (serum creatinine and cystatin $\mathrm{C}$ ) and tubular injury markers (NAG, KIM$1, \alpha$-GST and $\pi$-GST), using dominant (i.e. one or two copies of the minor allele) and additive (per 1-allele copy increase) genetic models. NAG, KIM-1, $\alpha$-GST and $\pi$-GST were log-transformed because of their skewed distribution. To account for the high proportion of levels below the detection limit for $\alpha$-GST and $\pi$-GST, Tobit regression with left censoring and the log-normal distribution was used
68

Nephron Clin Pract 2013;123:67-73

DOI: $10.1159 / 000351684$
Susantitaphong/Perianayagam/

Tighiouart/Liangos/Bonventre/Jaber 
Table 1. Characteristics of the cohort according to the TNFA rs1800629 genotypes

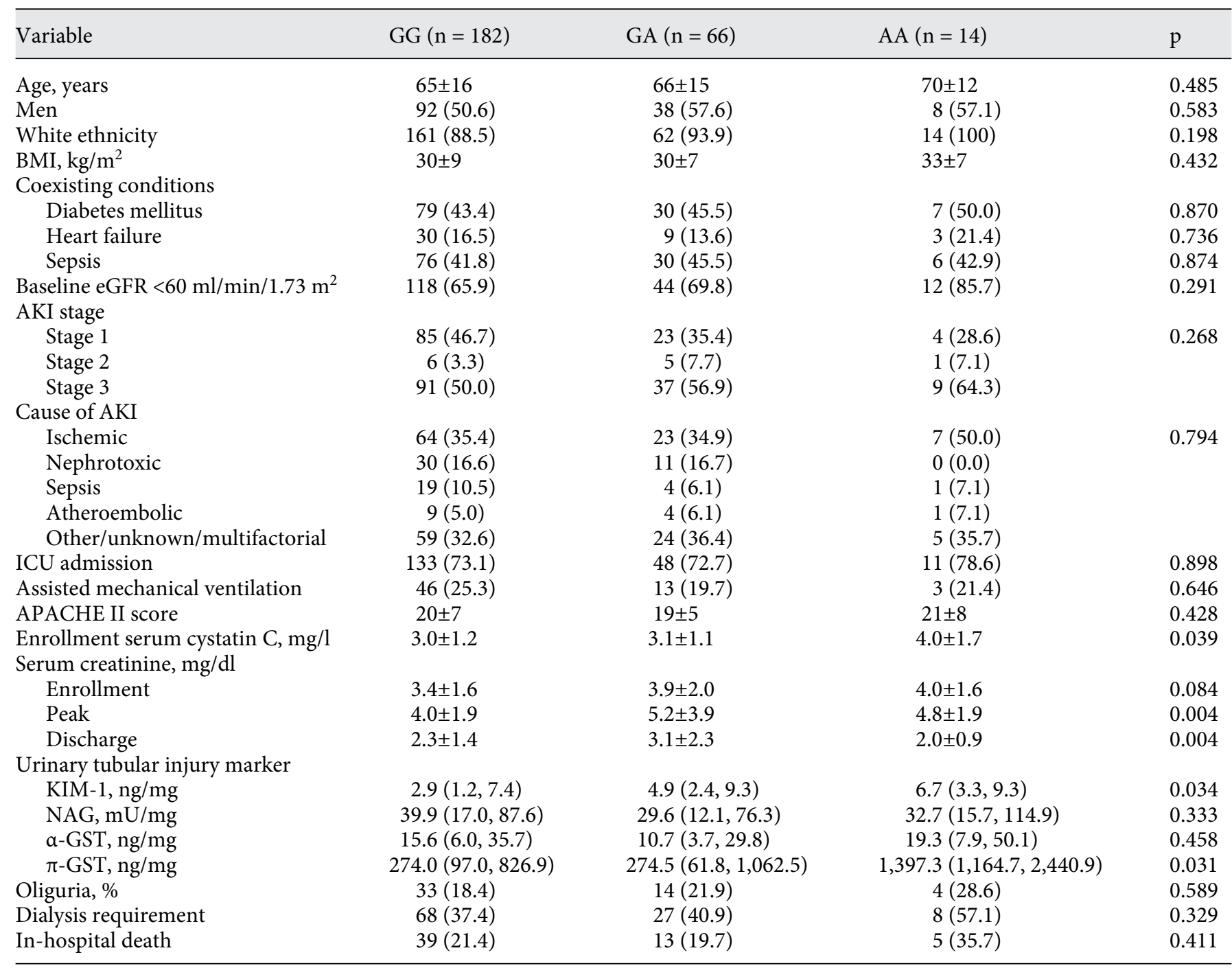

Continuous variables are presented as means (SD) or medians (25th and 75 th percentile), and categorical variables as $\mathrm{n}(\%)$.

[32]. All the analyses were adjusted for sex, race, age, baseline eGFR, sepsis, and dialysis requirement. Results from the regression models are provided as a parameter estimate or relative ratio with $95 \%$ CI. All statistical analyses were performed using the SAS software (version 9.2, SAS Institute, Cary, N.C., USA). Differences were considered statistically significant at $\mathrm{p}>0.05$.

\section{Results}

\section{Characteristics of the Cohort Stratified by TNFA Genotypes}

Genotyping was performed on a total of 262 subjects. The test for Hardy-Weinberg equilibrium showed devia- tion from expected genotype frequencies $\left(\chi^{2}=5.46 ; \mathrm{p}=\right.$ 0.02 ). The TNFA gene polymorphism had a minor allele frequency of $18 \%$. The mean age of the cohort was 66 years, $53 \%$ were men, $91 \%$ were of white ethnicity, $73 \%$ were in the intensive care unit, and $43 \%$ had sepsis. The mean baseline eGFR was $53 \mathrm{ml} / \mathrm{min} / 1.73 \mathrm{~m}^{2}$, and the mean APACHE II score was 20. At enrollment, $53 \%$ of patients had stage 3 AKI and $20 \%$ had oliguria.

The characteristics of the cohort stratified by the TNFA rs1800629 genotypes are shown in table 1. In brief, demographic characteristics, coexisting conditions, and disease severity measures did not differ significantly among the genotype groups, except for a higher number of failed 
Table 2. Association of the TNFA rs1800629 polymorphism with filtration markers

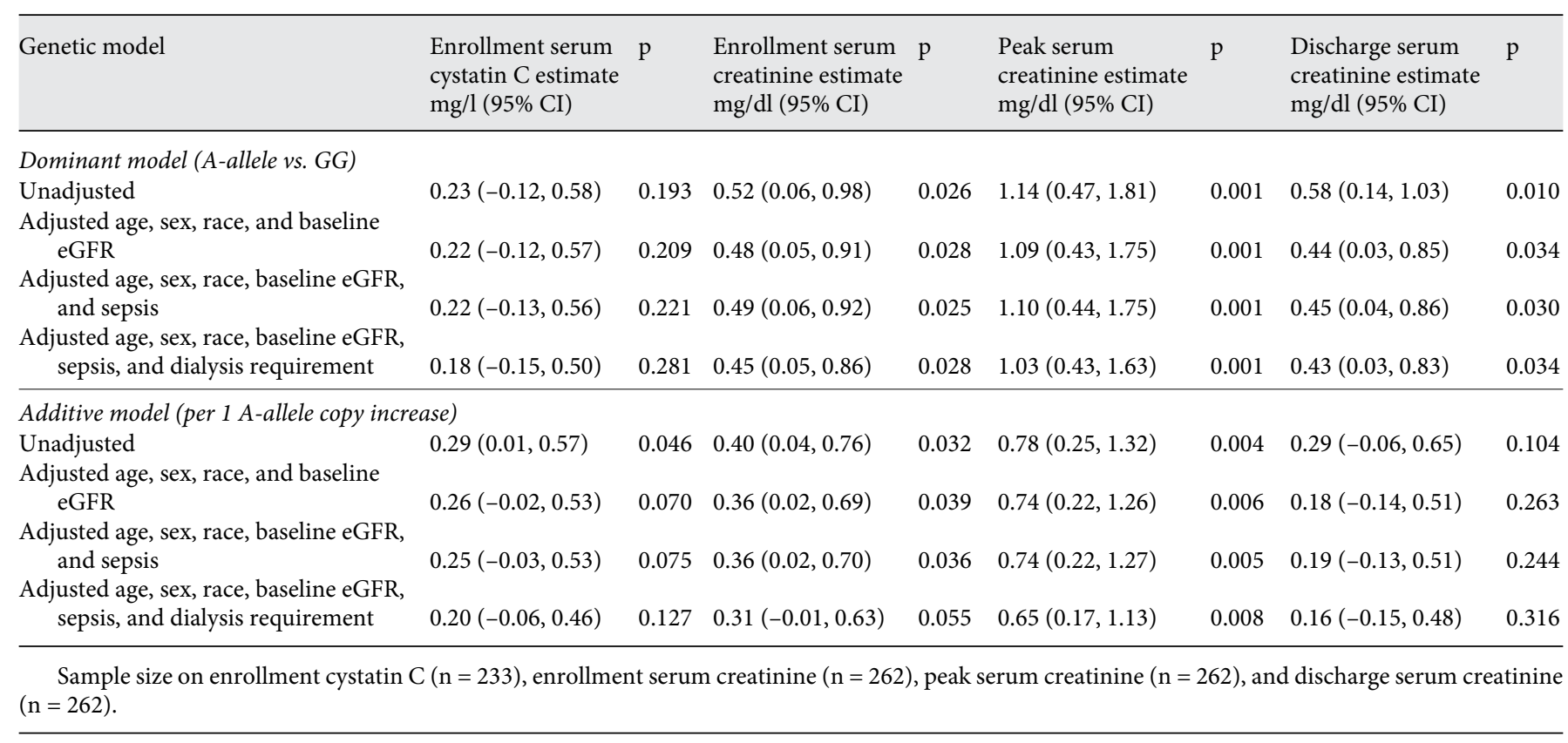

organs, as defined by the MOF score, in the TNFA rs1800629 minor A allele (GA/AA genotype) group ( $\mathrm{p}=$ 0.01 ; figure 1).

As shown in table 1, with regard to the filtration markers, compared to the GG genotype group, carriers of the TNFA rs1800629 GA and AA genotype tended to have a higher enrollment $(\mathrm{p}=0.08)$, peak $(\mathrm{p}=0.004)$, and discharge $(\mathrm{p}=0.004)$ serum creatinine. Compared to the GG and GA genotype groups, carriers of the TNFA rs1800629 AA genotype tended to have a higher enrollment cystatin $C(p=0.04)$. In terms of urinary markers, compared to the GG genotype group, carriers of the TNFA rs1800629 GA and AA genotype tended to have a higher urinary KIM-1 level ( $\mathrm{p}=0.03$ ), and the AA genotype group tended to have a higher urinary $\pi$-GST level $(\mathrm{p}=0.03)$.

\section{Association of TNFA Genotypes with Filtration and} Tubular Injury Markers

The results of the multivariable dominant and additive genetic models are displayed in tables 2 and 3. There were some significant associations between the TNFA rs1800629 minor A allele and both filtration and tubular injury markers. Indeed, in the dominant models, after adjustment for sex, race, age, baseline eGFR, sepsis, and dialysis requirement, compared with the GG genotype, the TNFA rs1800629 minor A allele group had a higher en-

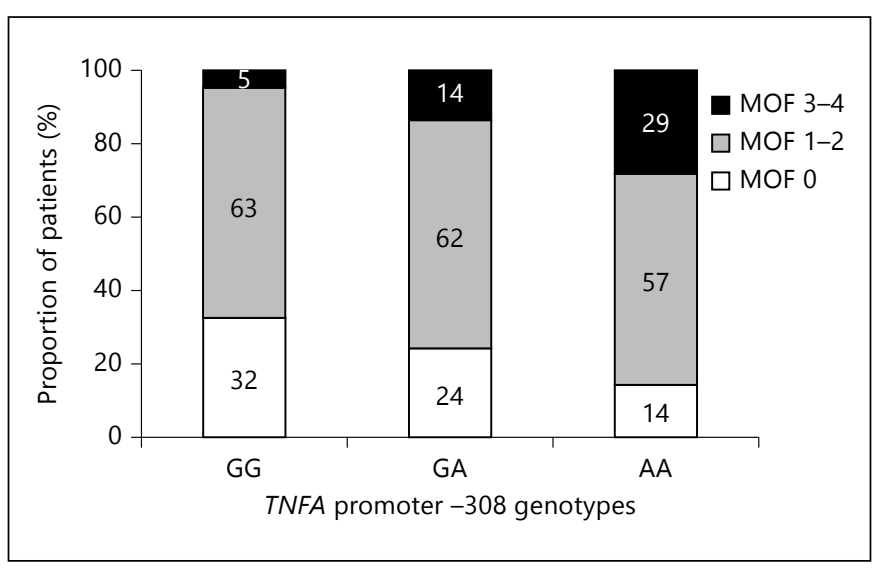

Fig. 1. MOF score stratified by the TNFA rs1800629 gene polymorphism. $\mathrm{p}=0.012$ by $\chi^{2}$ test.

rollment serum creatinine ( $\mathrm{p}=0.028)$, a higher peak serum creatinine $(\mathrm{p}=0.001)$, and a higher serum creatinine at hospital discharge $(\mathrm{p}=0.034)$. Similar but weaker associations were observed with serum creatinine in the multivariable additive models. There was a weak association between the TNFA rs1800629 AA genotype group and higher enrollment serum cystatin $C(p=0.039)$ in the unadjusted additive model, which became nonsignificant in the multivariable analysis. 
Table 3. Association of the TNFA rs1800629 polymorphism with tubular injury markers

\begin{tabular}{|c|c|c|c|c|c|c|c|c|}
\hline Unadjusted & $0.87(0.61,1.25)$ & 0.459 & $0.64(0.29,1.39)$ & 0.259 & $1.21(0.58,2.51)$ & 0.618 & $1.75(1.16,2.65)$ & 0.008 \\
\hline $\begin{array}{l}\text { Adjusted age, sex, race, and baseline } \\
\text { eGFR, }\end{array}$ & $0.86(0.61,1.20)$ & 0.365 & $0.70(0.32,1.54)$ & 0.372 & $1.26(0.60,2.64)$ & 0.544 & $1.77(1.18,2.65)$ & 0.006 \\
\hline $\begin{array}{l}\text { Adjusted age, sex, race, baseline eGFR, } \\
\text { sepsis, and dialysis requirement }\end{array}$ & $0.81(0.59,1.12)$ & 0.205 & $0.70(0.32,1.55)$ & 0.381 & $1.23(0.59,2.56)$ & 0.587 & $1.73(1.16,2.59)$ & 0.008 \\
\hline \multicolumn{9}{|c|}{ Additive model (per 1 A-allele copy increase) } \\
\hline Unadjusted & $0.94(0.70,1.26)$ & 0.669 & $0.79(0.42,1.47)$ & 0.452 & $1.30(0.72,2.35)$ & 0.384 & $1.61(1.14,2.26)$ & 0.007 \\
\hline $\begin{array}{l}\text { Adjusted age, sex, race, and baseline } \\
\text { eGFR, }\end{array}$ & $0.93(0.71,1.23)$ & 0.625 & $0.83(0.44,1.56)$ & 0.562 & $1.39(0.77,2.52)$ & 0.278 & $1.62(1.16,2.26)$ & 0.005 \\
\hline
\end{tabular}

Sample size on urinary NAG $(\mathrm{n}=234), \alpha-G S T(n=243), \pi-G S T(n=246)$, and KIM-1 $(n=204)$.

Similarly, in the dominant model, after adjustment for sex, race, age, baseline eGFR, sepsis, and dialysis requirement, compared with the GG genotype, the TNFA rs1800629 minor A allele group had a higher urinary KIM-1 ( $\mathrm{p}=0.008)$. A similar association was observed in the multivariable additive models.

In the dominant models, after adjustment for sex, race, age, and sepsis, compared with the GG genotype, the TNFA rs1800629 minor A-allele group had a higher MOF score of 0.26 (95\% CI: $0.03,0.49 ; \mathrm{p}=0.024)$. This association persisted in the additive model (data not shown).

Finally, sensitivity analyses restricted to white subjects did not affect any of the adjusted analyses.

\section{Discussion}

In the present study, we examined in a cohort of hospitalized adults with AKI the association between a functional polymorphism (at position -308; rs1800629) located in the promoter region of the TNFA gene, which is a pivotal proinflammatory cytokine, and kidney disease severity, including levels of glomerular filtration and tubular injury markers. We found that carriers of the TNFA rs1800629 minor A allele had higher levels of filtration markers, including higher serum creatinine and cystatin $\mathrm{C}$, and higher urinary tubular injury markers, including
KIM-1 and $\pi$-GST. Carriers of the TNFA rs1800629 minor A allele also experienced more organ system dysfunction, as evidenced by a higher MOF score.

Studies have previously evaluated the relationship of the TNFA rs1800629 polymorphism with adverse outcomes in several acute clinical settings [33], including acute myocardial infarction, acute pancreatitis, and sepsis [34-36]. In a study of 603 patients, carriers of the rs1800629 TNFA minor A allele had significantly higher levels of biomarkers of cardiac injury, including troponin $\mathrm{I}$, creatine kinase- $\mathrm{MB}$, and lactate dehydrogenase [34]. These findings are consistent with our results demonstrating an independent association between carriers of the TNFA rs1800629 minor A allele and higher levels of filtration (serum creatinine and cystatin C) and tubular injury (KIM-1 and $\pi$-GST) markers in a cohort of patients with AKI.

In our study, we demonstrated that carriers of the TNFA rs1800629 minor A allele also had higher serum creatinine at hospital discharge. We can only speculate as to whether carriers of this genetic marker are at an increased long-term risk of developing chronic kidney disease. In a cohort of 231 patients with chronic kidney failure and 180 healthy matched control subjects, the TNFA rs1800629 minor A allele was a strong risk modifier for development of kidney failure [37]. In kidney transplant recipients, a similar association has been observed 
whereby the TNFA rs1800629 minor A allele was associated with an increased risk of chronic allograft nephropathy [38].

We observed an association between the TNFA rs1800629 minor A allele and organ system dysfunction, as defined by the MOF score. A similar association has previously been observed in patients with acute pancreatitis [35], sepsis [21], and community-acquired pneumonia [36]. A recent meta-analysis demonstrated an association between the TNFA rs1800629 minor A allele carrier and development of sepsis [39]. The association between the TNFA rs1800629 minor A allele and a higher MOF score is consistent with a similar association observed in a cohort of patients with chronic kidney disease and a higher burden of comorbidities [40]. Although prior studies of patients with sepsis or AKI requiring dialysis demonstrated an association between the TNFA rs1800629 minor A allele carrier and an adjusted increased risk of death $[6,21]$, we were unable to demonstrate a similar association.

To our knowledge, this is the first study that examines the association between a functionally relevant polymorphism in the TNFA gene and AKI disease severity, as measured by levels of filtration and tubular injury markers. The heterogeneity of the cohort was offset by the selective inclusion of subjects with more advanced AKI requiring formal nephrology consultation. Although sizeable, our cohort was relatively small for the purpose of genetic studies; however, the participants were $91 \%$ white, which reduced the potential impact of race and ethnicity on genotype prevalence. There are, however, several study limitations that should be noted. The TNFA rs 1800629 polymorphism did not fulfill the Hardy-Weinberg equilibrium, which might be due in part to the relatively modest sample size of our study or natural selection. We did not have a second cohort to validate our findings in a replication cohort. Of the 103 patients (39\%) who required renal replacement therapy, 36 initiated dialysis prior to study enrollment (median of 1 day prior to study enrollment), which might have confounded the association of the TNFA rs1800629 polymorphism with serum creatinine and cystatin $\mathrm{C}$. To account for this confounding effect, we adjusted our analyses for dialysis requirement, which did not markedly affect the effect sizes. In our cohort, we had a higher prevalence rate of preexisting $\mathrm{CKD}$, as defined by eGFR $<60 \mathrm{ml} / \mathrm{min} / 1.73 \mathrm{~m}^{2}$ due to the selection criteria used to identify eligible patients with AKI, mainly the criteria of Hou et al. [24], which require higher absolute rises in serum creatinine according to the baseline serum creatinine value. All our multivariable analyses, however, are adjusted for the baseline eGFR, which did not markedly attenuate the effect sizes. Finally, although we found an association with AKI-related surrogate endpoints, we were unable to demonstrate an association with hard clinical endpoints.

In conclusion, the present study explores the complex nature of how a functionally relevant genetic variant in the TNFA gene might influence severity of kidney injury in patients with AKI, and supports the hypothesis that the study of polymorphisms of host genes as genetic risk markers in the setting of acute illnesses such as AKI has merit. Additional studies are needed to establish the mechanisms underlying the influence of the identified TNFA gene polymorphism on AKI disease severity traits.

\section{Acknowledgements}

This study was funded in part by grants from the National Institutes of Health: DK065102 and DK077751 (to Dr. Jaber), and DK083428 (to Dr. Perianayagam). This work was also made possible in part through an investigator-initiated research study funded by Argutus Medical Ltd., Dublin, Ireland (to Dr. Jaber), and an International Society of Nephrology funded Fellowship (to Dr. Susantitaphong).

\section{Disclosure Statement}

Dr. Bonventre is a coinventor on KIM-1 patents that are assigned to Partners Healthcare and licensed by Partners to Johnson and Johnson, Sekisui, Biogen Idec, R\&D, and BioAssayWorks. Dr. Bonventre is also a consultant for Sekisui. The other authors declare that they have no financial interests relevant to this work.

References

1 Chertow GM, Burdick E, Honour M, Bonventre JV, Bates DW: Acute kidney injury, mortality, length of stay, and costs in hospitalized patients. J Am Soc Nephrol 2005;16:33653370.

-2 Liangos O, Wald R, O’Bell JW, Price L, Pereira BJ, Jaber BL: Epidemiology and outcomes of acute renal failure in hospitalized patients: a national survey. Clin J Am Soc Nephrol 2006; $1: 43-51$.

-3 Mehta RL, Kellum JA, Shah SV, Molitoris BA, Ronco C, Warnock DG, Levin A: Acute Kidney Injury Network: report of an initiative to improve outcomes in acute kidney injury. Crit Care 2007;11:R31.

4 Metnitz PG, Krenn CG, Steltzer H, Lang T, Ploder J, Lenz K, Le Gall JR, Druml W: Effect of acute renal failure requiring renal replacement therapy on outcome in critically ill patients. Crit Care Med 2002;30:20512058.
72

Nephron Clin Pract 2013;123:67-73

DOI: $10.1159 / 000351684$
Susantitaphong/Perianayagam/

Tighiouart/Liangos/Bonventre/Jaber 
5 Wald R, Quinn RR, Luo J, Li P, Scales DC, Mamdani MM, Ray JG: Chronic dialysis and death among survivors of acute kidney injury requiring dialysis. JAMA 2009;302:1179-1185.

-6 Jaber BL, Rao M, Guo D, Balakrishnan VS, Perianayagam MC, Freeman RB, Pereira BJ: Cytokine gene promoter polymorphisms and mortality in acute renal failure. Cytokine 2004; $25: 212-219$.

7 Liangos O, Balakrishnan VS, Pereira BJ, Jaber BL: Cytokine single nucleotide polymorphism. Role in acute renal failure. Contrib Nephrol. Basel, Karger, 2004, vol 144, pp 63-75.

8 Haase-Fielitz A, Haase M, Bellomo R, Dragun D: Genetic polymorphisms in sepsis- and cardiopulmonary bypass-associated acute kidney injury. Contrib Nephrol. Basel, Karger, 2007, vol 156, pp 75-91.

-9 Perianayagam MC, Liangos O, Kolyada AY, Wald R, MacKinnon RW, Li L, Rao M, Balakrishnan VS, Bonventre JV, Pereira BJ, et al: NADPH oxidase p22phox and catalase gene variants are associated with biomarkers of oxidative stress and adverse outcomes in acute renal failure. J Am Soc Nephrol 2007;18:255-263.

10 Kolyada AY, Tighiouart H, Perianayagam MC, Liangos $\mathrm{O}$, Madias NE, Jaber BL: A genetic variant of hypoxia-inducible factor-1alpha is associated with adverse outcomes in acute kidney injury. Kidney Int 2009;75:1322-1329.

- 11 Alam A, O'Connor DT, Perianayagam MC, Kolyada AY, Chen Y, Rao F, Mahata M, Mahata $\mathrm{S}$, Liangos O, Jaber BL: Phenylethanolamine Nmethyltransferase gene polymorphisms and adverse outcomes in acute kidney injury. Nephron Clin Pract 2010;114:c253-c259.

12 Perianayagam MC, Tighiouart H, Nievergelt CM, O'Connor DT, Liangos O, Jaber BL: CYBA gene polymorphisms and adverse outcomes in acute kidney injury: a prospective cohort study. Nephron Extra 2011;1:112-123.

13 Perianayagam MC, Tighiouart H, Liangos O, Kouznetsov D, Wald R, Rao F, O'Connor DT, Jaber BL: Polymorphisms in the myeloperoxidase gene locus are associated with acute kidney injury-related outcomes. Kidney Int 2012;82:909-912.

-14 Bonventre JV, Weinberg JM: Recent advances in the pathophysiology of ischemic acute renal failure. J Am Soc Nephrol 2003;14:21992210.

15 Kinsey GR, Li L, Okusa MD: Inflammation in acute kidney injury. Nephron Exp Nephrol 2008;109:e102-e107.

16 Akcay A, Nguyen Q, Edelstein CL: Mediators of inflammation in acute kidney injury. Mediators Inflamm 2009;2009:137072.

17 Lee DW, Faubel S, Edelstein CL: Cytokines in acute kidney injury (AKI). Clin Nephrol 2011; 76:165-173.
18 White LE, Hassoun HT: Inflammatory mechanisms of organ crosstalk during ischemic acute kidney injury. Int J Nephrol 2012;2012: 505197.

19 Kadiroglu AK, Sit D, Atay AE, Kayabasi H, Altintas A, Yilmaz ME: The evaluation of effects of demographic features, biochemical parameters, and cytokines on clinical outcomes in patients with acute renal failure. Ren Fail 2007;29:503-508.

20 Jaber BL, Liangos O, Pereira BJ, Balakrishnan VS: Polymorphism of immunomodulatory cytokine genes: implications in acute renal failure. Blood Purif 2004;22:101-111.

21 Mira JP, Cariou A, Grall F, Delclaux C, Losser MR, Heshmati F, Cheval C, Monchi M, Teboul JL, Riche F, et al: Association of TNF2, a TNF-alpha promoter polymorphism, with septic shock susceptibility and mortality: a multicenter study. JAMA 1999;282:561-568.

22 Tang GJ, Huang SL, Yien HW, Chen WS, Chi CW, Wu CW, Lui WY, Chiu JH, Lee TY: Tumor necrosis factor gene polymorphism and septic shock in surgical infection. Crit Care Med 2000;28:2733-2736.

23 Yende S, Quasney MW, Tolley E, Zhang Q, Wunderink RG: Association of tumor necrosis factor gene polymorphisms and prolonged mechanical ventilation after coronary artery bypass surgery. Crit Care Med 2003;31:133140.

24 Hou SH, Bushinsky DA, Wish JB, Cohen JJ, Harrington JT: Hospital-acquired renal insufficiency: a prospective study. Am J Med 1983;74:243-248.

-25 Levy MM, Fink MP, Marshall JC, Abraham E, Angus D, Cook D, Cohen J, Opal SM, Vincent JL, Ramsay G: 2001 SCCM/ESICM/ACCP/ ATS/SIS International Sepsis Definitions Conference. Crit Care Med 2003;31:1250-1256.

26 Knaus WA, Draper EA, Wagner DP, Zimmerman JE: APACHE II: a severity of disease classification system. Crit Care Med 1985;13: 818-829.

27 Knaus WA, Wagner DP: Multiple systems organ failure: epidemiology and prognosis. Crit Care Clin 1989;5:221-232.

28 Levey AS, Bosch JP, Lewis JB, Greene T, Rogers N, Roth D: A more accurate method to estimate glomerular filtration rate from serum creatinine: a new prediction equation. Modification of Diet in Renal Disease Study Group. Ann Intern Med 1999;130:461-470.

29 Perrey C, Turner SJ, Pravica V, Howell WM, Hutchinson IV: ARMS-PCR methodologies to determine IL-10, TNF-alpha, TNF-beta and TGF-beta 1 gene polymorphisms. Transpl Immunol 1999;7:127-128.

30 Wilson AG, Symons JA, McDowell TL, McDevitt HO, Duff GW: Effects of a polymorphism in the human tumor necrosis factor alpha promoter on transcriptional activation. Proc Natl Acad Sci USA 1997;94:3195-3199.
31 Liangos O, Perianayagam MC, Vaidya VS, Han WK, Wald R, Tighiouart H, MacKinnon RW, Li L, Balakrishnan VS, Pereira BJ, et al: Urinary $\mathrm{N}$-acetyl-beta-(D)-glucosaminidase activity and kidney injury molecule- 1 level are associated with adverse outcomes in acute renal failure. J Am Soc Nephrol 2007;18:904912.

32 Tobin J: Estimation for relationships with limited dependent variables. Econometrica 1958;26:24-36.

33 Jaber BL, Pereira BJ, Bonventre JV, Balakrishnan VS: Polymorphism of host response genes: implications in the pathogenesis and treatment of acute renal failure. Kidney Int 2005;67:14-33.

34 Antonicelli R, Olivieri F, Cavallone L, Spazzafumo L, Bonafe M, Marchegiani F, Cardelli M, Galeazzi R, Giovagnetti S, Perna GP, et al: Tumor necrosis factor-alpha gene $-308 \mathrm{G}>\mathrm{A}$ polymorphism is associated with ST-elevation myocardial infarction and with high plasma levels of biochemical ischemia markers. Coron Artery Dis 2005; 16:489-493.

- 35 Bishehsari F, Sharma A, Stello K, Toth C, O'Connell MR, Evans AC, Larusch J, Muddana V, Papachristou GI, Whitcomb DC: TNF-alpha gene (TNFA) variants increase risk for multi-organ dysfunction syndrome (MODS) in acute pancreatitis. Pancreatology 2012;12:113-118.

36 Waterer GW, Quasney MW, Cantor RM, Wunderink RG: Septic shock and respiratory failure in community-acquired pneumonia have different TNF polymorphism associations. Am J Respir Crit Care Med 2001;163: 1599-1604.

37 Manchanda PK, Kumar A, Kaul A, Mittal RD: Correlation between a gene polymorphism of tumor necrosis factor-alpha (G/A) and endstage renal disease: a pilot study from north India. Clin Chim Acta 2006;370:152-157.

38 Nikolova PN, Ivanova MI, Mihailova SM, Myhailova AP, Baltadjieva DN, Simeonov PL, Paskalev EK, Naumova EJ: Cytokine gene polymorphism in kidney transplantation - impact of TGF-beta 1, TNF-alpha and IL-6 on graft outcome. Transpl Immunol 2008;18:344-348.

-39 Teuffel O, Ethier MC, Beyene J, Sung L: Association between tumor necrosis factor-alpha promoter $-308 \mathrm{~A} / \mathrm{G}$ polymorphism and susceptibility to sepsis and sepsis mortality: a systematic review and meta-analysis. Crit Care Med 2010;38:276-282.

40 Balakrishnan VS, Guo D, Rao M, Jaber BL, Tighiouart H, Freeman RL, Huang C, King AJ, Pereira BJ: Cytokine gene polymorphisms in hemodialysis patients: association with comorbidity, functionality, and serum albumin. Kidney Int 2004;65:1449-1460. 